\title{
O DESAFIO DE ENSINAR PRÁTICAS DE LEITURA EM ESFERAS EDUCACIONAIS
}

\author{
Aline Cassol Daga ${ }^{1}$ \\ Mary Elizabeth Rizzatti \\ Sabatha Catoia Dias ${ }^{3}$
}

\begin{abstract}
RESUMO
Este artigo constitui uma discussão e base teórica e praxiológica que tematiza a horizontalização das práticas de leitura nos processos de escolarização. Tem como objetivo propor a compreensão do ato de ler sob a perspectiva da erudição, tanto quanto advogar em favor do alargamento dessa perspectiva, de modo a abranger práticas de leitura que têm lugar no cotidiano das sociedades contemporâneas. Defende uma ação educacional em que professores, bibliotecários e gestores assumam o papel de agentes de letramento, desencadeando e implementando projetos de letramento, de modo a fomentar práticas de leitura, na dimensão erudita do ato de ler, tanto quanto em sua dimensão profissional e cotidiana, em atenção às práticas de letramento que caracterizam os estudantes vindos de entornos socioculturais e econômicos diversos, o que implica diversidade nos níveis de escolarização e na natureza do contato com as práticas de leitura. A discussão fundamenta-se teoricamente em estudos do letramento, a partir de autores como Brian Street e Angela Kleiman.
\end{abstract}

Palavras-chave: Leitura. Práticas de letramento. Projetos de letramento.

\footnotetext{
${ }^{1}$ Mestre, e-mail: alinecdaga@gmail.com

2Doutora, e-mail: mary.rizzatti@terra.com.br

${ }^{3}$ Mestre, e-mail: sabathadias@gmail.com
} 


\section{INTRODUÇÃO}

Discutir a ação do educacional na formação escolar/acadêmica do leitor implica refletir sobre o que é leitura, tanto quanto refletir sobre o conceito de letramento e seus desdobramentos, tendo presente a proposta de uma ação protagonista do coordenador pedagógico, do professor e do bibliotecário no agenciamento de um conjunto de fazeres, organizados sob forma de projetos de letramento, na busca por consolidar efetivamente uma ação institucional voltada para a implementação das práticas de leitura.

\section{DA LEITURA PARA AS LEITURAS: A POSTURA AGENTIVA DO COORDENADOR PEDAGÓGICO E DO BIBLIOTECÁRIO NA FORMAÇÃO DO LEITOR}

Ao longo da história do processo de escolarização, que reflete e constitui concepções da História humana, o ato de ler se construiu como uma atividade intimamente vinculada à erudição, a elevados níveis de formação escolar. Sob essa perspectiva, ler significava ler livros, preferencialmente livros literários, os quais sempre tiveram as bibliotecas como seus territórios mais sagrados. Assim, ser leitor habitual, ser leitor contumaz implicava ser leitor de livros literários e, por via de consequência, ser frequentador habitual de bibliotecas tinha profundas relações com tomar emprestados livros dessa natureza. A herança escolar incorporou esse ideário de modo que habituação em leitura tornou-se sinônimo de habituação em leituras de livros literários, e as bibliotecas, sob vários aspectos, tornaramse instituições de prevalência deles. Evidentemente essa é uma concepção enriquecedora, que deve ser reiteradamente alimentada, mas que, hoje, precisa ser ressignificada.

Vivemos em uma sociedade crescentemente mais marcada pelos usos da modalidade escrita da língua, fenômeno a que temos chamado grafocentrismo e que pode ser ilustrado com a menção de exemplos como o fato de que estudos revelam haver cerca de 150 sites - prevalência da escrita - na internet para cada habitante do planeta (A NOTÍCIA..., 2010, p. 14) e que o uso de dados escritos é, hoje, maior do que o uso de voz nos Estados Unidos - um trilhão e quinhentos bilhões de mensagens em 2009 - 50\% a mais do que 0 as ligações telefônicas (informação verbal) ${ }^{1}$. Paralelamente a isso, tablets e Ipads vêm se instituindo como dispositivos de acesso a acervos on-line crescentemente mais numerosos. Trata-se de exemplos ilustrativos de como as sociedades contemporâneas, sobretudo a partir do advento das novas tecnologias, têm lançado mão da modalidade escrita da língua em substituição à modalidade oral em interações cotidianas e, no caso dos livros, exemplo de como a circulação de acervos on-line vem ganhando paulatinamente espaços expressivos. Para perceber isso, basta evocarmos situações prosaicas do dia a dia a exemplo de quantos de nós temos substituído ligações telefônicas por e-mails ou torpedos ou, em muitos entornos, como a recorrência a obras on-line tem caracterizado cada vez mais a busca por informações.

${ }^{1}$ Jornal Nacional, setembro de 2010. 
Trata-se, como podemos constatar em nossas vivências cotidianas, de uma substantiva instauração dos usos da modalidade escrita da língua nas relações sociais (FISCHER, 2006) e de uma silenciosa expansão no tratamento do livro como suporte. $E$, se essa implementação está se processando, como consequência direta, ocorre a ampliação das demandas pelo ato de ler textos em diferentes suportes. Precisamos nos tornar leitores proficientes de textos também em outras configurações, desde a leitura que nos é requerida para a mobilidade em hipertextos até a leitura que nos é requerida para nos movermos no cotidiano.

Em se tratando da ação do coordenador pedagógico e do bibliotecário, essa ressignificação do ato de ler precisa reverberar nas ações e nas configurações que caracterizam a escola como instituição em que o ato de ler ganha contornos especialmente importantes. Paralelamente ao desafio histórico de formar o leitor da literatura canônica e o leitor da literatura científica, no livro como suporte físico em papel, instaura-se um novo desafio: formar o leitor que se move com proficiência no mar de informações que as novas tecnologias disponibilizam aos sujeitos do nosso tempo histórico, sem, no entanto, render-se à tecnoburocracia, do que trataremos à frente.

Discutir a ação do coordenador pedagógico e do bibliotecário sob esse ponto de vista implica supor uma atitude agentiva no processo de gerenciamento da formação escolar do leitor. Ao educador contemporâneo não parece ser mais possível manter uma atitude apenas de resposta a demandas instituídas; é preciso criar essas mesmas demandas, instigando novas práticas de leitura.

Possivelmente a primeira grande questão que deva ser considerada em se tratando desse novo leitor, é a compreensão de que lemos para diferentes propósitos. Assim, não podemos tratar de leitura, mas de leituras, dada a natureza diversa a que esse processo atende. Geraldi (1997) sintetiza as razões pelas quais lemos: lemos para nos informar, lemos por prazer, lemos para estudar um texto e lemos por pretexto para fazer alguma coisa - como ler um romance para, a partir dele, produzir o enredo de um filme. Assim, a leitura literária atende prevalecentemente a um desses propósitos: ler por fruição, por prazer. É certo, reiteramos que essa leitura precisa ser intensamente exercitada nas instituições escolares - se não por outras razões, porque ela tende a humanizar o homem -, mas, paralelamente a esse exercício, importa compreender que estamos diante de um novo leitor que empreende diferentes leituras; agir em favor da formação desse novo leitor requer, preliminarmente, conhecer a natureza grafocêntrica das sociedades contemporâneas e a natureza dinâmica da informação, tanto quanto compreender a importância de a escola/ universidade se tornar uma instituição agenciadora das novas leituras.

Desse modo, ser leitor habitual não é comportamento isomórfico ou restrito à leitura de livros literários. Atualmente, nossas demandas de leitura respondem a questões de mobilidade social mais ampla e de empoderamento e essencialidades, o que coloca para as instituições educacionais - e singularmente para as bibliotecas - o compromisso de ressignificarem os seus processos de formação do leitor, depreendendo o papel que thes cabe no novo contexto histórico que vem se desenhando, sobretudo a partir do advento 
das novas tecnologias. Esse compromisso seguramente ganha contornos especialmente importantes em uma instituição como o Serviço Nacional de Aprendizagem Industrial (SENAI), que forma profissionais para as diferentes áreas da atividade humana.

\section{IMPLICAÇÕES DO CONCEITO DE LETRAMENTO NA HORIZONTALIZAÇÃO DAS PRÁTICAS DE LEITURA}

Na seção anterior, tematizamos a transcendência do conceito de leitura para o conceito de leituras, registrando que a nova configuração da sociedade contemporânea requer do educador, do gestor e do bibliotecário uma ação protagonista na formação do leitor nessas diferentes leituras. Essa discussão demanda uma reflexão sobre o conceito de letramento, de cujas implicações nos ocuparemos aqui.

Na década de 1990, o termo letramento ganhou lugar no cenário nacional (KLEIMAN, 1995; SOARES, 1998), trazendo consigo a proposta de uma nova compreensão sobre a modalidade escrita da língua, tomada, até então, em uma perspectiva vinculada eminentemente à escolarização e à erudição. O conceito de letramento diz respeito aos diferentes usos sociais da escrita que os mais variados agrupamentos humanos levam a termo, com diferentes propósitos e diferentes implicações de empoderamento. A discussão que empreendemos na seção anterior sobre a forma múltipla como lidamos contemporaneamente com a escrita deriva das teorizações sobre letramento.

Para as finalidades desta discussão, importa termos presente que as teorizações sobre letramento suscitam a compreensão de que, na formação do leitor, é preciso considerar que as pessoas chegam às instituições escolares - e às bibliotecas - trazendo consigo vivências de leitura características do grupo sociocultural e econômico a que pertencem, as chamadas práticas de letramento (STREET, 1988). Essas vivências implicam valorações atribuídas aos materiais escritos e experiências com leituras, as quais se constroem nas relações intersubjetivas mantidas no interior dos diferentes grupos socioculturais e econômicos.

Nessa reflexão, é importante considerar que, até meados do século passado, as populações que tinham acesso à escolarização plena eram estratos sociais cujas práticas de letramento tendiam a ser muito semelhantes às práticas de letramento valorizadas pela escola/universidade (SOARES, 2002; ZAVALA, 2010). Assim, o bibliotecário convivia com estudantes na maioria das vezes familiarizados com a leitura de obras da literatura canônica, tanto quanto familiarizados com a literatura de consulta, dado que as famílias dos estratos sociais de origem desses estudantes tendiam a ter livros em casa. Coleções de obras de autores como Machado de Assis e José de Alencar, assim como enciclopédias conhecidas e dicionários de prestígio constituíam (e ainda o fazem ladeadas pelo acesso a bancos de dados on-line) acervos familiares nesses estratos sociais. Sob esse ponto de vista, ainda que tais estudantes não estivessem habituados à leitura, obras dessa natureza não lhes eram de todo absoluta novidade. 
Com a ampliação do acesso à escolarização, que se deu sobretudo na segunda metade do século passado, a escola/universidade passou a receber estudantes oriundos de estratos socioculturais e econômicos cujas práticas de letramento começaram a se distinguir substancialmente das práticas de letramento características das esferas acadêmica e escolar. Esses grupos não traziam - tanto quanto não trazem hoje -, como herança familiar, a valoração de leituras prestigiadas nessas esferas, passando a ser submetidos à necessidade de adotarem comportamentos completamente novos em suas rotinas de leitura e, sob vários aspectos, inteiramente dissociados de suas vivências até então. Mesmo em se tratando do ensino médio e do ensino superior, essa realidade parece persistir, o que sinaliza para a inoperância de muitos processos de escolarização fundamental no que respeita à familiarização dos estudantes, nos anos iniciais de escolarização, com leituras distintas de suas vivências.

Zavala (2010, p.72), ao escrever sobre o impacto desse processo na universidade, registra:

[...] enquanto no passado o ensino superior estava reservado a uma elite educada que havia sido preparada para a experiência em escolas que não diferiam tanto das universidades e em lares que não diferiam tanto daqueles de seus professores, agora a massificação do ensino superior [...] colocou sobre a mesa diferentes maneiras de pensar, atuar, valorizar e falar, que entram em conflito.

Assim, muitos estudantes que chegam aos bancos escolares - nas universidades ou na educação básica -, embora sejam considerados, em princípio, aptos a participar de uma série de práticas discursivas que tem lugar nesses espaços, costumam levar algum tempo para se ambientar nesse novo "mundo de letramento" (HAMILTON; BARTON; IVANIC, 1994), porque, dentre outros fatores, as leituras com que se defrontam são muito diferentes das leituras de domínio até então.

Essas considerações têm papel substantivo na redefinição das ações do educador, do gestor educacional e do bibliotecário. Se, historicamente, sobretudo a função deste último profissional limitava-se a atender às demandas externalizadas pelos frequentadores das bibliotecas, hoje, ao que parece, cabe também a ele - tanto quanto a gestores e educadores - ressignificar as práticas de letramento dos estudantes, orientando as leituras, provocando novas demandas, instigando novas buscas, de modo a hibridizar os letramentos vernaculares - práticas de letramento que caracterizam o entorno sociocultural e econômico desses estudantes - com os letramentos dominantes - práticas de letramento que caracterizam o universo escolar e acadêmico (STREET, 2003) e sobre as quais se fundam a ação e a configuração das bibliotecas.

Essa necessidade de hibridização tem especial significado em se tratando do SENAI, em razão da dimensão profissionalizante que caracteriza as atividades dessa instituição. Eis o desafio do novo educador: agir na formação do leitor para facultar aos estudantes a habituação com as leituras necessárias à constituição de seu aporte profissional, tanto quanto lhes facultar a habituação em leituras cujo conteúdo veicule os saberes 
universalizados, aquele conjunto de conhecimentos que não tem finalidade imediata e pragmática, mas que é constituidor da humanidade do homem, da criticidade do homem do empoderamento do homem.

Essa hibridização entre letramentos vernaculares e letramentos dominantes - dentre estes últimos os usos da escrita que caracterizam os fazeres profissionais imediatos, mas necessariamente também os usos da escrita que caracterizam a cultura da Humanidade em um espectro mais amplo - parece ser o grande desafio da ação das instituições educacionais na formação do leitor na contemporaneidade. E, para que essa ação seja deflagrada, importa que o educador esteja consciente da ampla diversidade existente entre as práticas de letramento do entorno social de origem de muitos estudantes e as práticas de letramento do espaço educacional formal. Com base nessa consciência um fazer conjunto com professores, gestores e bibliotecários de modo a propor ações que contribuam para que essa hibridização se dê, já que não é mais possível esperar que os estudantes tragam de seus estratos familiares capital cultural (BOURDIEU; PASSERON, 1975) convergente com o capital cultural escolar e acadêmico. Esse capital cultural precisa ser apropriado pelos estudantes na instituição educacional formal, o que requer a ação efetiva e articulada dos agentes nesses espaços.

\section{AAÇÃOEDUCACIONALNAFORMAÇÃODOLEITOR:ENTREATECNOBUROCRACIA E A CULTURA MASSIVA DE UM LADO, E AS ESSENCIALIDADES HUMANAS E O EMPODERAMENTO DE OUTRO.}

Nesse processo de formação desse novo leitor, com as implicações suscitadas pelas práticas de letramento, instaura-se um dos mais efetivos desafios para as instituições educacionais contemporâneas na formação do leitor: a percepção da tecnoburocracia e da cultura massiva e a transcendência a elas. Expliquemos isso melhor.

Somos premidos, hoje, pela necessidade de resultados. Atividades de uma instituição como o SENAI convivem com essa premência cotidianamente, o que fica visível em indicadores de desempenho que precisam ser otimizados a cada período de tempo. Não podemos ficar alheios a eles sob pena de não compreendermos as bases sobre as quais o pensamento contemporâneo vem se construindo: busca constante de resultados otimais, eis uma característica de nosso tempo histórico, bem visível na educação em nível nacional. Paralelamente a essa característica, convivemos, também, com a forte projeção da cultura de massa que, no âmbito dessa discussão, materializa-se no pool de best-sellers que conquistam leitores de todas as idades.

Se, porém, não podemos deixar de estar atentos a traços marcantes da contemporaneidade como esses, importa, na ação institucional em favor da formação do leitor, transcender esses mesmos traços. Em se tratando da tecnoburocracia, por exemplo, ainda que devamos ser sensíveis ao fato de que lemos para diferentes propósitos em nossa mobilidade cotidiana, não podemos nos descuidar na consciência de que a priorização 
dessas leituras funcionais do dia a dia responde a uma necessidade prática imediata e precisa ser considerada, ou seja, devemos educar o leitor para essas diferentes leituras. Não, podemos, no entanto, entender que basta formamos esse leitor para fins pragmáticos porque, se o fizermos, estaremos nos limitando a responder a exigências de uma sociedade tecnologizada e burocratizada que requer leitores capazes de se mover no dia a dia apenas, respondendo a necessidades imediatas de natureza profissional ou de convivência cotidiana.

É necessário que nossa ação tenha como meta a formação do leitor de diferentes leituras: leituras que potencializem sua ação profissional cotidiana, mas leituras que o façam refletir sobre essa mesma ação profissional, sobre as finalidades a que se presta, sobre o tipo de homem e de sociedade a que serve, sobre as relações de poder que ajuda a reiterar ou a pôr em xeque. Não podemos agir em favor da formação de leitores de obras e textos que tão somente respondam a suas necessidades imediatas de ação. Temos de formar leitores de obras e textos que tematizem as bases e as finalidades sobre as quais se organizam e operacionalizam suas ações profissionais. Eis o leitor empoderado, crítico e reflexivo - e não só o leitor operativo e procedimental - que nos cabe formar. O mesmo vale em se tratando da chamada literatura de aeroporto. Não podemos negar a sua existência, a preferência de inúmeros leitores por esse tipo de obra, tanto quanto não podemos negar o potencial dessas obras na conquista de novos leitores, mas é preciso transcender a elas.

Para que esse processo de hibridização entre práticas de letramento já instituídas (sejam elas representativas de entornos socioculturais e econômicos genuínos, sejam elas movidas por demandas da tecnoburocracia e da cultura massiva) e novas práticas de letramento se consolide, importa uma ação institucional efetiva na qual o educador precisa assumir uma postura de agente mobilizador e articulador de ressignificações na formação do leitor, operando sob forma de projetos consequentes de ação, em articulação com a instituição educacional como um todo, de modo a instituir e a desenvolver políticas de leitura que tornem vivazes as esferas escolar e acadêmica, fazendo delas espaços de um acervo múltiplo, capaz de conciliar os desafios tecnológicos da leitura em suportes eletrônicos com as obras clássicas da literatura científica e da literatura canônica, na ruptura dos limites entre a geografia da biblioteca e a geografia das salas de aula. Nesse processo, dessacralizar a biblioteca talvez seja um primeiro movimento necessário para Ihe restituir a vida. Assim, orientar as leituras, escolher itens que comporão o acervo - o livro, mas não só o livro -, divulgar de forma instigadora esses itens, encaminhar o leitor para essas leituras é parte da postura agentiva que defendemos para o educador contemporâneo na formação do leitor. 


\section{O COORDENADOR PEDAGÓGICO E O BIBLIOTECÁRIO COMO AGENTES DE LETRAMENTO OPERANDO POR MEIO DE PROJETOS DE LETRAMENTO}

Organizar a ação da instituição por meio de projetos requer sensibilidade às particularidades das realidades locais, porque os projetos têm propósitos de ressignificar essas realidades, buscando possíveis respostas para fragilidades, problemas, necessidades e demandas ou, por outro lado, visibilizando interesses dos estudantes e professores ou, ainda, valorizando determinadas características locais e contribuindo para o fortalecimento das identidades ali construídas. Assim, quando organizamos projetos, precisamos ficar atentos para a importância de esses projetos significarem de fato nos espaços educacionais em que serão desenvolvidos. Desse modo, tais projetos não devem ser uniformizantes, extensivos a realidades muito amplas, porque, nesses casos, tendem a perder o estreito vínculo que devem manter com o universo específico em que serão desenvolvidos. Kleiman (2009, p. 4 grifos nossos), autora que propõe o conceito de projeto de letramento, escreve:

O projeto de letramento se origina de um interesse real na vida dos alunos, e sua realização envolve o uso da escrita, isto é, envolve a leitura de textos que, de fato, circulam na sociedade e a produção de textos que serão lidos, em um trabalho coletivo de alunos e professor, cada um segundo sua capacidade. Assim, o projeto de letramento pode ser considerado como uma prática social em que a escrita é utilizada para atingir algum fim, que vai além da mera aprendizagem formal da escrita, transformando objetivos circulares como "escrever para aprender a escrever" e "ler para aprender a ler" em ler e escrever para compreender e aprender aquilo que for relevante para o desenvolvimento e a realização do projeto. Os projetos de letramento requerem um movimento que vai da prática social para o conteúdo (seja ele uma informação sobre um tema, uma regra, uma estratégia ou procedimento) nunca o contrário.

Para implantar um projeto de letramento, exige-se que o agente educacional esteja apto para identificar os interesses desses estudantes, tanto quanto para detectar necessidades e demandas do grupo em que eles se inserem, desenvolvendo a habilidade para descobrir onde e como encontrar dados e informações que sejam relevantes para delinear o projeto e para alcançar os objetivos traçados. $O$ agente educacional precisa fazer encaminhamentos de modo a instigar as novas leituras e as ressignificações das práticas de letramento já instituídas.

Kleiman (2009) ressalta que o ponto de partida para um projeto de letramento são interesses dos estudantes em relação a questões que fornecerão o tema do projeto, o que significa que a experiência do aluno é central e que o processo vai contemplar fazeres e ações que, nesse caso, permitam a implementação das práticas de leitura. Uma exigência básica para o projeto ser bem sucedido é que, nesse caso, haja hibridização entre letramentos vernaculares e letramentos dominantes (ROJO, 2009). 
Trabalhar com projetos de letramento implica organizar a ação da biblioteca em absoluta sintonia com a ação da escola como um todo, tendo como foco as práticas sociais. Esse trabalho exige que o educador assuma a função de agente de letramento. Escreve Kleiman (2007, p. 414):

Se, por um lado, todos somos agentes, exercendo nossa ação sobre objetos do mundo, pelo fato de sermos humanos, a agência social é uma condição de poucos, aqueles que agem na coletividade, exercendo sua ação com os outros, em função dos objetivos de um grupo social.

Ser um agente de letramento requer assumir uma postura protagonista junto aos estudantes e à comunidade escolar, articulando os interesses de leitura que os membros daquele grupo compartilham, organizando o grupo para uma ação conjunta, gerando movimentos sociais e contribuindo para a tomada de decisões que modifiquem favoravelmente a realidade local (KLEIMAN, 2007), nesse caso, no que respeita ao papel da instituição educacional na formação do leitor crítico, reflexivo, autônomo, empoderado, informado. Quanto ao bibliotecário, especificamente, não pode mais ser concebido como o paladino silencioso de um espaço sagrado; precisa se converter no mobilizador de um espaço vivaz.

Para a Kleiman (2007, p. 422):

[...] aprender a ler e a escrever é um processo de construção de identidades para os alunos de grupos dominados, mais pobres, de tradição oral, porque envolve a aprendizagem de práticas sociais de outros grupos, em sua maioria, alheios a seus interesses, modos de ação e modos de falar.

Assim, atuar como agente de letramento implica desencadear uma ação solidária, agindo em favor do empoderamento das pessoas por meio dos projetos de letramento com foco na implementação das práticas de leitura. Sob essa perspectiva, a ação da biblioteca exige do bibliotecário propor projetos que tenham significado para os estudantes e para as comunidades, de modo que as práticas de leitura que forem empreendidas ao longo do projeto contribuam para que ocorram mudanças favoráveis na coletividade. 


\title{
CONSIDERAÇÕES FINAIS
}

A contemporaneidade exige das instituições educacionais uma atividade mais efetiva na formação do leitor para as diferentes leituras, com o necessário cuidado de não empreender uma ação que tão somente atenda a demandas da tecnoburocracia instituída, atentando para a dimensão pragmática da leitura no cotidiano, mas que seja sensível a essa dimensão tanto quanto à urgência de formar o leitor de obras e textos que traduzam a essencialidade da condição humana e as implicações mais complexas dos fazeres profissionais. Para dar conta disso, as instituições precisam organizar uma ação que congregue bibliotecários, professores e gestores em torno de projetos de letramento, atentos às práticas de letramento locais, mas focados no alargamento dessas práticas em favor do crescimento e do empoderamento dos diferentes grupos sociais por meio também das práticas de leitura.

\section{THE CHALLENGE OF TEACHING READING PRACTICE IN EDUCATIONAL ENVIRONMENTS}

\begin{abstract}
This article represents a discussion and theoretical and praxeological foundation that describes the level of reading practices in schooling processes. The aim is to propose an understanding of the act of reading from the perspective of learning, as well as advocate for the extension of this perspective, to include reading practices that take place in everyday life of contemporary societies. It supports an educational action where teachers, librarians and administrators assume the role of agents of literacy, triggering and implementing literacy projects in order to promote reading practices, in classical dimension of the act of reading as much as in his professional and everyday dimension in attention to literacy practices that characterize students from different sociocultural and economic environments, which implies diversity in levels of schooling and the nature of contact with the reading practices. The discussion is based on theoretical studies of literacy, from authors like Brian Kleiman and Angela Street.
\end{abstract}

Keywords: Reading. Literacy practices. Literacy projects. 


\section{REFERÊNCIAS}

A NOTÍCIA é só o começo. Veja, São Paulo, n.2162, p. 14, 28 de abr. 2010. Disponível em: <http://veja.abril.com.br/acervodigital/home.aspx>. Acesso em: 23 jul. 2012

BOURDIEU. P.; PASSERON, J.C. A reprodução. Rio de Janeiro: Francisco Alves, 1975.

FISCHER, Steven Roger. História da leitura. Trad. Claudia Freire. São Paulo: UNESP, 2006.

GERALDI, João Wanderley. Portos de passagem. 4. ed. São Paulo: Martins Fontes, 1997.

HAMILTON, Mary; BARTON, David; IVANIC, Roz (Orgs.). Worlds of literacy. Clevedon, England: Multilingual Matters, 1994.

KLEIMAN, Angela. (Org.) Os significados do letramento. Campinas (SP): Mercado das Letras, 1995.

Professores e agentes de letramento: identidade e posicionamento social. Revista de Filologia, v.7, p. 409-424, set. 2007.

Projetos de letramento na educação infantil. Revista Caminhos em Linguística Aplicada, v. 1, n. 1, p. 1-10, 2009.

ROJO, Roxane. Letramentos múltiplos, escola e inclusão social. São Paulo: Parábola, 2009.

SOARES, Magda. Letramento: um tema em três gêneros. Belo Horizonte: Autêntica, 1998.

Português na escola: história de uma disciplina curricular. In: BAGNO, Marcos (Org.). Linguística da norma. São Paulo: Loyola, 2002. p. 155-177.

STREET, Brian. Abordagens alternativas ao letramento e desenvolvimento. Teleconferência Unesco Brasil sobre 'Letramento e Diversidade', outubro de 2003.

.Literacy practices and literacy myths. In: SALJO, R. (Org.) The written world: studies in literacy thought and action. Nova lorque: Springer-Verlag, 1988.

ZAVALA, Virgínia. Quem está dizendo isso?: letramento acadêmico, identidade e poder no ensino superior. In: VÓVIO, Claudia; SITO, Luanda; GRANDE, Paula de (Orgs.). Letramentos. Campinas, SP: Mercado de Letras, 2010. 


\section{SOBRE AS AUTORAS}

\begin{tabular}{|l} 
Possui licenciatura em Letras - Língua Portuguesa e mestrado em Linguística \\
pela Universidade Federal de Santa Catarina (UFSC). Tem experiência com \\
revisão e design instrucional de materiais didáticos para cursos de graduação a \\
distância e com tutoria na EaD. Atualmente, é doutoranda no Programa de Pós- \\
Graduação em Linguística da UFSC, integra o Núcleo de Pesquisas em Linguística \\
Aplicada (NELA) e é professora colaboradora na Universidade Estadual de \\
Santa Catarina (UDESC), onde trabalha com as disciplinas de Alfabetização e \\
Letramento, Análise e Produção Textual e Conteúdos e Metodologias do Ensino \\
da Linguagem no Curso de Pedagogia a Distância.
\end{tabular}

\begin{tabular}{|l|l||} 
Possui graduação em Letras, mestrado em Linguística e Letras pela Pontifícia \\
Universidade Católica do Rio Grande do Sul e doutorado em Letras pela \\
Universidade Federal do Rio Grande do Sul. É professora adjunta da da \\
Universidade Federal de Santa Catarina - UFSC. Tem experiência na área de \\
Linguística e Letras, com interesse por estudos sobre ensino e aprendizagem \\
de língua materna, estudos acerca de relações entre cultura escrita, identidade \\
e processos de escolarização, bem como acerca de relações entre práticas \\
sociais de uso da língua e inserção versus mobilidadesocial; atua em temas \\
relacionados a formação de professores de Língua Portuguesa,alfabetismo e \\
Mary Elizabeth sociais da escrita. \\
Cerutti-Rizzatti
\end{tabular}

Possui licenciatura e bacharelado em Letras - Língua Portuguesa e mestrado
em Linguística pela Universidade Federal de Santa Catarina (UFSC). Tem
experiência com docência nos anos finais do Ensino Fundamental e com
tutoria no ensino a distância (EaD). Atualmente, é doutoranda no Programa
de Pós-Graduação em Linguística da UFSC e integra o Núcleo de Pesquisas
em Linguística Aplicada (NELA). Seu objeto de pesquisa é leitura, com foco no
processo de ensino e de aprendizagem na Educação Básica.

